\title{
9 Touring the videogame city
}

\author{
Bobby Schweizer
}

\section{Visiting San Francisco virtually}

There is something special about exploring videogame worlds, particularly those that re-create well-known places. These virtual worlds are hybrid spaces that draw on real places to inform their design and are brought to life through computer code that allows us to interact with and navigate them (Bogost \& Klainbaum, 2006; Schweizer, 2013; Whalen, 2006). In games, the activity of tourism is performed within media itself to represent both our fascination with recreating the familiar and our awe at the computer's ability to simulate lifelike worlds to explore. However, the common act of exploring is not always synonymous with touring, which needs to be considered as a meaningfully distinct activity. San Francisco - a place that has captivated media producers of all types - has seen numerous digital recreations in videogames over the years that encourage touristic behaviour. When its iconic geography and architecture are constructed using 3D graphics to be navigated by a videogame player, games set in the Golden Gate City produce a convincing illusion. In one magazine review for a game set in virtual San Francisco, critic Kati Hamza wrote: "What's most impressive . . . is the genuine feel of being in an authentic city. Streets, trees, bridges and 2.429 buildings create a huge environment to suss out - you can have a lot of fun just sightseeing while you fly around" (Hamza, 1991). In another review for a different game set in San Francisco, Philip Kollar wrote that the virtual recreation "captures the flavour of a place I love" (Kollar, 2016). Both of these game reviews marvel at the ability of a virtual world to capture the essence of real place - despite the fact that the two games to which they refer to were made over 20 years apart. Killing Cloud, to which Hamza refers, was released in 1991 for home computers such as the Amiga, Atari ST, and IBM PCs. Watch Dogs 2, on the other hand, was released in 2016 for PlayStation 4, Xbox One, and Microsoft Windows.

The graphical and processing capabilities of the hardware that allowed these games to run may be decades apart, but, at their core, both had the effect of bringing a place to life. Their players seek out familiar landmarks to marvel at the computer representations. In Killing Cloud, the player patrols 


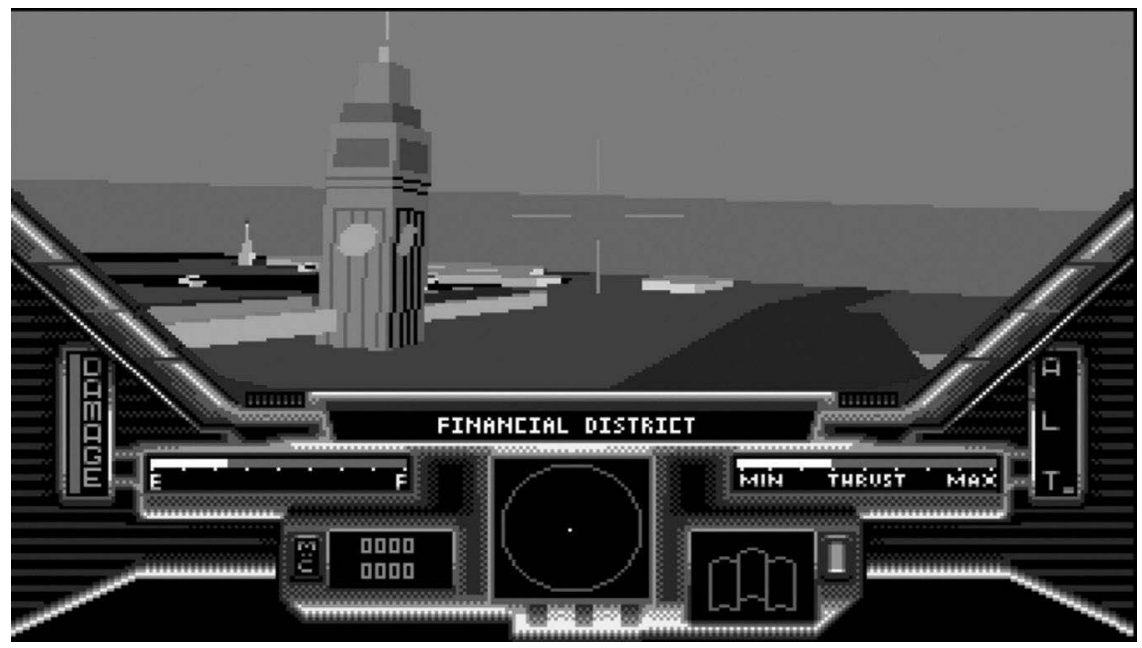

Figure 9.1 San Francisco depicted in Killing Cloud (1991) for the Commodore Amiga.

Source: Image by author.

San Francisco from above on a futuristic hoverbike. San Francisco's tall buildings emerge from the top of the poisonous cloud that hangs low over the city and stand out as distinct landmarks without the visual obstruction typically experienced at ground level (Figure 9.1). The density of San Francisco is abstracted into one or two buildings per city block. A few are modelled to look like their real-world counterparts - the Ferry building, the Transamerica Pyramid, the Hyatt Regency on Embarcadero - but most are placeholders that stand in for a type of building: simple rectangular skyscrapers downtown, Monopoly-piece-shaped houses in residential areas. Compared to other games from the era, the technological novelty of Killing Cloud's polygonal graphics and the freedom to move about the city provided for a touristic experience. In one review of the game, David Upchurch (1991) wrote: “The polygon graphics aren't quite the fastest I've ever seen, but they're more than fast enough, and the ability to set detail level means it's up to you whether you'd rather sight-see or get on with the job at hand". And, in support of this, the game even featured a "touring" mode that allowed players with more powerful computers to enable greater draw distances and more visual detail.

When re-creating real places virtually, it's difficult not to draw comparisons between how we play a game and the way we tour cities. In game reviews from magazines and the Internet, web forum discussions, screenshots shared online, and videos posted to YouTube, players have discussed 
"sight-seeing" Watch Dogs 2. Executive editor Dan Stapleton (2016) of online gaming magazine IGN wrote:

This is a great open world map, and I'm not just saying that because was born in the Bay Area and have lived here for almost my entire life ... it's surreal to be in a car chase and suddenly look up and see something like Moscone Centre, the Palace of Fine Arts, the Painted Ladies, Fisherman's Wharf, or Stanford University. I'd recommend it as virtual tourism, especially if you've been here before and want a refresher.

And Game Spot editor Peter Brown (2016) wrote "Ubisoft does a great job of presenting the Bay Area in an attractive way that feeds intrepid tourists an impressive variety of sights". Tourism, as these quotes and many others allude to, is a frequent part of the conversation about game spaces. The foundational work of tourism in games that this chapter builds upon comes from scholars Michael and Jacqueline Salmond, who proposed that all players are tourists who enact a touristic lifestyle in game worlds that is similar to that in real worlds (Salmond \& Salmond, 2016: 155). The "gamer-tourist" that they describe is motivated by novel experience, adventure, and the feeling of being in a real place. This desire to visit new fantastic virtual worlds is similar to the urge to travel, and visiting new places causes us to look at the environment with a gaze of "interest and curiosity" (Urry \& Larsen, 2011: 1). Yet not all play in videogame spaces is equivalent to tourism because of the goal-oriented structures of games. Tourism is a secondary practice - behaviour that emerges because the videogame city imaginary establishes expectations and produces anticipation about a mediated space. The player in a videogame is able to adopt a touristic mindset through this imaginary, and the act of touring is prefigured by the presentation of something that should be known and is worth exploring (MacCannell, 1999). Thus, Salmond and Salmond's definition of the gamer-tourist needs to be revised to focus specifically on how tourism is performed by players.

\section{Defining tourism in games}

In existing game tourism literature, the idea of encountering new spaces in games - particularly those built in three-dimensional polygonal graphics engines that position a player-controlled figure in a traversable world - is used to draw comparisons to manoeuvring our own bodies through unfamiliar places as if we were tourists. In their most recent edition of The Tourist Gaze, Urry and Larsen (2011) describe nine qualities that typify touristic practices in contemporary society. Three of these qualities put tourism into opposition with work or commuting, one involves journeying to new places, two involve its socially negotiated nature, two others describe how the object of tourist interest is formed by pre-figuring the sight to be seen, and 


\section{Bobby Schweizer}

the final one illustrates how tourists beget more tourism. Yet the figure of the gamer-tourist often conflicts with Urry and Larsen's qualities: games' goal-oriented play actually structures the experience as more laborious than recreational.

The types of games that are open to touristic behaviour, and thus Salmond and Salmond's broad definition of the gamer-tourist, tend to be driven by stories or exploration in a digitally constructed environment navigated by a player controlling a character in three-dimensional space - everything from the open-world cities of Grand Theft Auto and arid landscapes of Borderlands (2009) to the aquatic wonders of Endless Ocean (2008). Urry and Larsen contrast the tourist gaze with "non-tourist social practices", such as those that involve home life and work, noting that what may seem like encountering novel views is not always described by the participant as touring. This tension between player experience and narrative can be seen, for example, in Marvel's Spider-Man (2018). Its version of New York City may be a stunningly modelled 3D environment, but in the diegesis of the game, Peter Parker is hardly on vacation. The game's urban vistas are met with the effort required to progress through the game and the constant forward momentum of the narrative. Playing the game may be a leisure activity, but taking on the role of Spider-Man means facing conflict and challenge while proceeding along a prescribed path. Peter Parker - former photographer for the Daily Bugle - decides it would be useful to "calibrate" the map he uses to track events across the city by taking photos of familiar landmarks. For the player, this is like being a tourist, and the game's "photo mode" allows them to change visual filters and focal length before saving these images to their PlayStation. But for Spider-Man, this is just another day on the job. So, though Salmond and Salmond are right to characterize games as supporting touristic practices, a better definition is required to distinguish goal-oriented gameplay from the other parts of the game that permit and encourage touristic behaviour.

To support touristic behaviour, the game's world needs to be framed for the player as pre-existing and "known by others" to promote the idea that there is something worth touring. For this reason, this chapter focuses on videogame cities that adapt and translate real places in their virtual construction. Navigable space (contrasted with the city as backdrop) also promotes player agency and gives them time to reflect on the world outside of goal-oriented gameplay. For example, although the climactic military battle of the first-person shooter game Homefront (2011) takes place on the Golden Gate Bridge with San Francisco in the background, this scenario is not touring because there, deviation from the prescribe path means failure in the game. By way of contrast, the touristic mindset is well represented in the Yakuza series of games, as illustrated by this quote from game journalist Luke Plunkett (2012):

Tokyo is one of my favourite cities on Earth, and while I've been there plenty of times, I always look forward to going back. It's nine hours and 
$\$ 1000$ away, though, so that's usually out of the question. But when I slide a Yakuza disc into my PS3 I can, for a night, make a half-assed trip, complete with karaoke-laden adventures and endless runs to convenience stores for snacky treats.

It is not just that the game world is a new place for the player to explore it's that some sort of pre-existing knowledge is brought to the game that inspires players to seek out specific locations or experiences. Some are very specific, like Plunkett's knowledge of Tokyo, but other players come to videogame cities knowing that there are sights to see even without having visited the city before. This knowledge is a part of the "urban imaginary" that prefigure our travels because we "negotiate the reality of cities by imagining "the city" as a concept (Donald, 1999: 18). When referring to "the city", the mental image is a conglomeration of the qualities of all urban spaces. And, when referring to a specific city, the imaginary takes into account the "overflow of media images and narratives coexist with personalized memories, historical events, architectural constructions, and lived experiences" (Jaguaribe, 2007: 102). Imaginaries are the convergence point between how "the city affects imagination and how the city is imagined", because the physicality of urban space matters less than the lived spaces of representation (Bridge \& Watson, 2008: 7). Examples of imaginaries include "literary productions, notions of urban myth, memory and nostalgia in the city and its environs, or to the sociological imagination re-cast within the changing realm of new technologies and forms of communication" (Westwood \& Williams, 1997: 1). Imaginaries, as portrayals of the city, convey city-ness beyond their architectural construction. Videogames, as a medium, draw heavily on other forms of mediated cities while providing a unique imaginary of the city whose immateriality is not only visually represented but is experienced through virtual spatial exploration and player agency (Schweizer, 2013). Though not all toured videogame spaces are cities, this frequent form of representation is useful for establishing what constitutes the "touristic mindset" that makes certain kinds of videogame play unique.

\section{Framing the touristic mindset}

The roles we inhabit in games are complex and shape how we understand tourism. Salmond and Salmond extend their exploration-as-travel analogy further by saying that the game itself acts as a tour guide to lead the player through the environment (Salmond \& Salmond, 2016: 154-155). Based on this premise, they suggest that Grand Theft Auto: San Andreas (2005) uses its story, missions/goals, and characters to instruct the player what to do and how to get through the world. The game revolves around a protagonist named CJ who has returned from New York City to the impoverished neighbourhood (based on South Central Los Angeles) in which he grew up. The 


\section{Bobby Schweizer}

character of CJ is a "local", yet the player who controls him is not. If the fiction of the game explicitly defines the player's role opposite to tourist, under what circumstances do we separate the two? On the one hand, researcher Kiri Miller (2008) has described this kind of player as a tourist-ethnographer. Miller takes Grand Theft Auto: San Andreas and highlights how its gameplay and representations of inner-city Los Angeles gang life become a guided form of cultural tourism. We role-play as CJ in order to take this journey and observe with an anthropological gaze. The game, which is set in a faux 1990s California that extensively references popular films such as John Singleton's Boyz $n$ the Hood (1991) and the Hughes Brothers' Menace II Society (1993), provides a specific Los Angeles imaginary to tour. But while the missions in the game provide some sort of guided structure through the world, they don't necessarily encourage tourism in the ways described by tourism studies scholars. Other framing mechanisms are required to position the player as tourist.

It is not unusual for games to be framed by outside paratexts - advertisements, marketing material, instructions manuals - that draw parallels to travel and exploration. Supporting materials such as game walkthroughs (magazines or websites that step by step tell the player how to complete a game) have long been referred to as "guides". Typically, these guides are presented in a utilitarian manner, but creative authors have sometimes recontextualized as tourist guidebooks. For example, the Super Nintendo game EarthBound (1995) came with a strategy guide packaged in the box that depicted the player's journey through the world as an elaborate travel brochure. The "Travel Guide" contained information beyond the usual game walkthrough each of the game's towns and regions had a dedicated two-page spread with a travel brochure on one side and a fake newspaper front page on the other. For example, the starting location of Onett's brochure details the area's temperate climate, "scenic vistas", a "tourist favourite" spot called Giant Step, the arcade, and the library. Some of the images on the page are screenshots of the game's 16-bit graphics, but others are real photographs that help set the tone even though they do not accurately represent anything in the game. At the time of the game's release, strategy guides were typically sold separately, so having it included in every game box exposed the touristic mindset to many more players.

Instruction booklets are another way of preparing the player for the game they are about to encounter. The Grand Theft Auto trilogy of games released during the PlayStation 2 era (Grand Theft Auto III, Vice City, and San Andreas) each came packaged with elaborately themed fold-out maps and instruction booklets. Whereas GTA III (2001) framed this paratext as a general guide to the game's topology, notable characters, and daily life, Grand Theft Auto: Vice City (2002) explicitly titled its manual a "Tourist Guide". The booklet included local facts and history, a guide to "getting around", advice about "what to bring", and points of interest. Any player who chose to read this manual to whet their appetite for the game was provided with a 
neon-Miami imaginary represented in screenshots from the game that emulated photographic composition. The Vice City manual specifically refers to its reader as a visitor - an outsider much like the game's protagonist they are preparing to inhabit.

In-game elements can also promote feelings of tourism. The Assassin's Creed series fills its recreations of real historical cities with pop-up notifications of historical factoids that the player can learn more about by accessing an in-game database. For example, Assassin's Creed II (2009) is set in 15 th-century Italy, and the player visits recreations of cities such as Florence, Venice, and San Gimignano. Although certain elements of these places are anachronistic, the game presents a rhetoric of deep historical simulation by presenting lavish descriptions in an encyclopaedia (Dow, 2013). Wandering into the piazza in front of the Basilica di Santa Maria del Fiore triggers a pop-up message containing a narrative of its construction and history (rather than just names and dates). Though collecting these landmarks is not required for completing the game, the formal, educational presentation lends credence to the authenticity that encourages players to seek out these landmarks as a way of adopting a touristic approach to exploring the game's city beyond goal-oriented gameplay.

\section{Playing tourist}

Whether an individual chooses to call themselves a traveller or a tourist is a process of self-identification that is fostered by elements within the game. This is particularly true when the player and their character traverse the landscape together to perform activities explicitly labelled as "playing tourist". As the story of Grand Theft Auto: San Andreas (2004) unfolds, CJ finds himself leaving Los Santos (Los Angeles) for the city of San Fierro (based on San Francisco). During their time in San Fierro, the player encounters a series of optional game objectives: "snapshot" locations hidden throughout the city that the player can capture using game's camera item. These 50 locations - including the game's versions of the Golden Gate Bridge, Pier 39, Chinatown, and the Castro Theatre - demonstrate the touristic impulse. The objectives are portrayed in the game by round pink icons hovering above the points of interest in order to encourage players to look around and focus on the game's urban architecture. And, because both CJ and the player are new to the island of San Fierro, the idea of sight-seeing here is more appropriate than the Los Santos area of the game that CJ would have called home. Similarly, in Sleeping Dogs (2012), the protagonist character Wei Shen is a native of Hong Kong. However, he (and thus the player) is encouraged to think like a tourist when his American girlfriend asks if he will drive her around and snap a few photos with his phone for her blog. After gathering the shots, the mission concludes with Wei Shen remarking that it's "nice playing tourist in your own town". The use of an ingame camera item replicates our use of digital cameras that allows tourists 


\section{Bobby Schweizer}

to immediately review the activity of the moment (Bell \& Lyall, 2005). Touristic practices can be encouraged diegetically in-game through photography missions that give the option for exploratory play and reflection.

The "possessive spectator", as conceived by media scholar Eric Gordon (2010: 3), acts as an interpreter who reflects on their experience and understanding of a place by recording it. It creates a distinct mindset that transforms space as something to be used by many into space as something to be consumed by one. While paintings and writings have long fixed the image of the city for media consumption, the image of the modern city, as Gordon explains, derives from the development of photographic technology. During most of the 19th century in the United States, urban tourism was a limited category because American cities were spread far apart and had not yet been framed in terms of leisure or historical interest. However, the issue of distance was resolved as the railroad network made passenger travel more accessible and more comfortable such that people with moderate means could make short recreational trips. As a result, the tourism industry began to produce new, cohesive images of the city, including guidebooks and photographs (ibid: 15). The White City of the 1893 Chicago World's Columbian Exhibition was "the first instantiation of a city built to accommodate this emerging possessive spectatorship" in which its visitors "believed they could take control of the Concept-city, consuming it like any other media object" (ibid: 16-17). Most significant to this new way of experiencing the Fair's design was the Kodak "Brownie" camera, which allowed tourists to snap and possess their own views (ibid: 45-47). We can see the same process at work in the various ways videogame technology allows its players to possess space and, as a result, can see how videogame worlds are being reconfigured to accommodate and encourage possessive spectatorship.

Similar to the sight-seeing camera of Grand Theft Auto: San Andreas, game developers have recognized their player's desire to capture moments and have incorporated these tools directly into the game. The player-character's mobile phone in Grand Theft Auto IV (2008) and Saints Row The Third (2011) have camera apps that allow them to document their travels. And, even more recently, open-world games such as Grand Theft Auto V (2013), Yakuza 6 (2016), Watch Dogs 2 (2016), and Marvel's Spider-Man (2018) have incorporated the modern photographic form: the selfie. In Watch Dogs 2, for example, the camera is used as a justification for touring: visiting wellknown landmarks to take character selfies using the in-game camera will earn the player "followers" in the game's fictional social network.

As Dinhopl and Gretzel (2016) describe, selfies afford self-presentation that is "facilitated by distancing or othering the self and looking at oneself from an outside perspective" to situate oneself immediately in the moment. Rather than remove any traces of the player's representation in the world to pristinely capture the landscape, selfie modes inject the player-character's body into the scene. In-game tools that mimic photography, whether a point-and-shoot camera or a selfie mode, encourage players to think like 
possessive spectators as they tour the city's landscape. Players then further undergo their transformation into tourist when the activities of possession encounter methods of sharing their travels with others.

\section{Sharing the journey}

As videogame players become tourists, possessive acts quickly extend into the social practices akin to sharing vacation photos and writing travelogues. The most immediate connection to the long history of the tourist's gaze are screenshots that record individual moment. The practice of capturing screenshots produces a new relationship between player and game similar to tourists who chooses to take photographs. In screenshotting, "layers of identity inform the tourist/traveller in everything they record: what to record, how to record and the language used to describe events" (Salmond, 2016: 191). The ability to easily record moments from a videogame console connected to a TV is relatively recent, but in the early 2000s, players of personal computer games could use the Microsoft Windows "print screen" functionality to save a copy of the image on the monitor. Researcher Betsy Book (2003) described the documentarian impulse of travellers in online virtual worlds who take screenshots to commemorate social interactions, especially when visiting in-game recreations of wellknown landmarks. This practice has also been analysed by videogame scholar Cindy Poremba (2007), who articulated how screenshotting has extended into all manner of games by remediating techniques and conventions of photography. Players could take their screenshots and share them in photo galleries to online fan websites or post them to online discussion forums with narrative accompaniment. The process can be both personal ("look what I did in the game") or empirical ("look at places you can see in the game"). As Orvar Löfgren (2002: 74) says of taking travel photos while on holiday, it's not just the desire to save the memories that drives photography but the pleasure of creating something. For example, artist Raphael Smith (2013) performs elaborate photography in games such as Grand Theft Auto IV by installing software add-ons meant to create images beyond what is immediately available through the built-in screenshot function. These software add-ons can change the view from third to first person in order to remove the player's avatar and user interface; enhance visual features such as higher-resolution textures; create realistic conversions for 3D models like cars and trees; and provide tools that render lighting, colour tone, and saturation of the image as while it is being taken (Grubb, 2013). Smith even hosts these images on the photography website Flickr as a way of equating his digital work with lens-based cameras. The Heterotopias online game magazine is a similar endeavour that collects screenshots and essays that focus on representations of architecture in games. Both forms rhetorically position their game worlds as sites of serious inquiry, like a travel photographer who wishes to reveal the beauty and majesty 


\section{Bobby Schweizer}

of places we take for granted. From fans posting screenshots to forums to self-serious high-resolution, perfectly composed digital photographs, "the recording and preservation of the travel experience is fixed in the idealized performance of what it is to travel" (Salmond, 2016: 192). Deliberate acts of recording become the impulses of tourism.

Home consoles that were connected to televisions at the turn of the millennium, like the Sony PlayStation 2 or original Microsoft Xbox, did not give players easy access to recording technology. This meant that (barring special hardware) players who wanted to save their exploits would need to point a camera at their television. But with the release of the Sony PlayStation 4, the Microsoft Xbox One, and the Nintendo Switch, "share" buttons on the controller have given players quick access to capturing in-game events. Posting screenshots and sharing in-game photos show how the videogame tourist is increasingly engaged in the same kinds of practices as human tourists in physical places sharing their experiences on social media. As these tools and means of disseminating the photographs become more common, players follow Susan Sontag's aphorism that "the camera makes everyone a tourist", and their participation in the game world fluctuates between possessive spectator and sharing actor.

In the last five years, video capture and sharing have become prevalent in the realm of videogames. Gameplay videos uploaded to YouTube, livestreams broadcast to Twitch.tv, and even short clips posted on social media have allowed players to share their game-playing experiences. Game playing is by its nature temporal, and video can capture active performance of the player in a variety of ways. The different modes of capture or streaming can frame the tourism experience as either a record of previous events or a "live" broadcast of the act in real time. The raw footage captured by players may be uploaded in full or edited into highlights and clips. Players may choose to narrate their experiences while playing or compose and edit a video essay afterwards. Live-streaming gameplay may also involve an audience of viewers (typically in a chat room on a separate monitor or windowed alongside the game) discussing the ongoing events of a game. Evidence of these can be found in quantity on YouTube by searching for a game name alongside the term "tour". Searching the phrase "los santos tour" returns a huge number of videos about Grand Theft Auto V (Figure 9.2). In many of these, players seek out the game's real-world Los Angeles equivalents, evocative locations, or even references to the fictional places of the game's prequel Grand Theft Auto: San Andreas. In these videos, the player embodies both the role of possessive spectator and active interpreter. The informal "tours" in these videos cover wide ground: showing off landmarks or impressive visual features, dividing the area up geographically to showcase variety, tours of in-game activities, or even the lesser-known and hidden aspects of the game. Because of the accessibility of recording and streaming tools, these possessive spectators are transforming into amateur tour guides. 

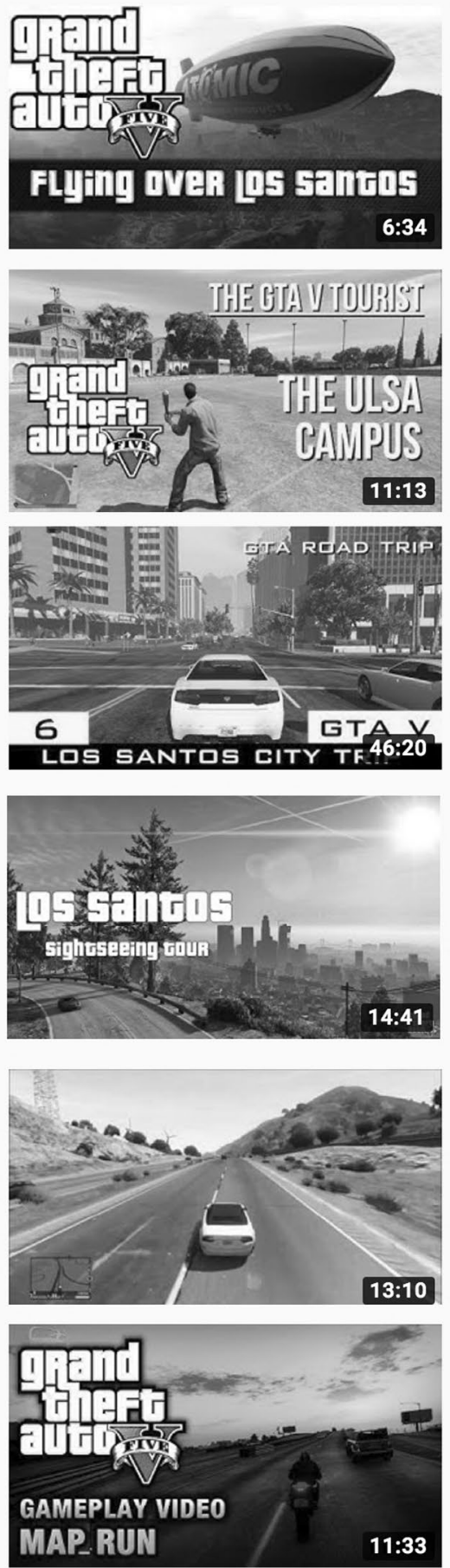

GTA V - A Tour over Los Santos with the Atomic Blimp [PS3] moebotzz $\cdot 2.3 \mathrm{~K}$ views $\cdot 5$ years ago Take a look on the Special Edition DLC Atomic Blimp and a tour over Los Santos and a short

The GTA V Tourist: University of San Andreas, Los Santos... Katzenwagen TV $\cdot 2.3 \mathrm{~K}$ views $\cdot 2$ years ago Hello and welcome to The GTA V Tourist series! :) Today, we'll be checking out the ULSA campus,

\section{The GTA V Tourist: Exploring} the main areas of Los Santos Katzenwagen TV $\cdot 17 \mathrm{~K}$ views $\cdot 2$ years ago Welcome to Episode 6 of Katzenwagen TV's GTA Road Trip series! In this episode, we take a tour

\section{GTA V Los Santos Sightseeing Tour} Cybermax TV $\cdot 913$ views $\cdot 2$ years ago Nice View's from this City.

\section{GTA: V - A Tour of Los}

\section{Santos}

TheVariedGamerHD $\cdot 30 \mathrm{~K}$ views $\cdot 5$ years ago $\mathrm{Hi}$ youtube friends and subscribers, Peter here bringing you another random video and this one

\section{GTA 5 - Map Run: Driving} Around Los Santos \& Blaine... GTA Series Videos $\bigcirc 265 \mathrm{~K}$ views 5 years ago This gameplay video shows how long it takes to drive all the way around the map in Grand Theft Related

Figure 9.2 Player-created tourism videos on YouTube.

Source: Image by author. 


\section{Bobby Schweizer}

\section{The spectator becomes the guide}

In tour videos, players explore with a set of expectations and varying levels of expertise and react spontaneously to what they encounter. A video titled "Touring the Real San Francisco in Watch Dogs 2" produced by online game magazine IGN shows how two players - Alanah from Australia and Marty the long-time San Francisco resident - interpret the game's virtual recreation of San Francisco (Pearce \& Sliva, 2016). The video begins in Dolores Park with Marty explaining that he will be acting as a tour guide to share some of his favourite places in the city. Alanah (and by proxy the viewer) are the audience of this tour, which is motivated by the game's fictional social media platform that rewards players with points for taking selfies in interesting places. Their first stop is the Castro Theatre, which prompts a brief discussion of the significance of the Castro neighbourhood. As they move on to their second location, the two discuss how this version of San Francisco is condensed for the game yet manages to capture "the layers of the city". Much of the tour is conducted while driving a car because it is a quick way to traverse long distances, so Marty is frequently shifting the direction of the viewpoint (which is based in a third-person perspective) to focus on points of interest the car is passing. As the tour continues, Alanah makes an interesting remark: as an Australian, she has not encountered any games about her own cities, so to explore a city that she has just recently moved to reminds her of the feeling New Yorkers or Los Angelinos must have when they see their cities represented in media. As the video tour comes to a close, Marty accidentally runs over a pedestrian, which causes the police to chase after him. He attempts to ignore and evade them but, upon exiting the car to take a selfie on the iconic winding Lombard Street, the police shoot his character to death and the game restarts. The video edits out the restart and the tour continues, but this unexpected event vividly demonstrates how touristic aspirations in open-world city games must always contend with the rules defined in the software's code.

Similar to the city tour of Watch Dogs 2's San Francisco conducted by Marty and Alanah, the persistent novelty of real places re-created virtually is evident in many videos that compare the references and their referents in virtual cities with real-world counterparts. Videos such as GamesRadar's Mafia 3 - New Bordeaux VS New Orleans - The City That Inspired the Game (Jarvis \& Houghton, 2016) and VortexStory's Driver VS Driv3r VS Real Life - Miami Map Comparison (VortexStory, 2017) take photos and footage of the real location and splice them together with in-game footage or screenshots. In the case of a well-known online publication like GamesRadar, the purpose of a comparison tour is to attract attention to the publication's website and YouTube channel to harness hype around of the release of the game. But in the case of VortexStory, an independent video producer with only a small number of YouTube followers and whose channel is focused on sharing the ins and outs of the mildly popular 2004 game 
Driver 3, we can see an earnestness in the desire to act as a tour guide. This genre of video is not limited to comparisons between real-world locations and their videogame counterparts, however. As an example of another kind of mediated imaginary, players of Grand Theft Auto $V$ have documented how its expanded version of Los Santos makes reference to places featured in the version of Los Santos shown in Grand Theft Auto: San Andreas nearly a decade earlier. These videos demonstrate new forms of game tourism in which the object of interest no longer has an index in the real world but rather whose significance is defined within the media culture of games itself.

\section{Game tourism as transformation}

This chapter has focused on videogame cities that were created to replicate or reference existing cities of the world to establish the connection between realworld and virtual-world tourism. Extensive knowledge of these real cities by videogame players is not required for them to be experienced as a tourist even the knowledge that the Seattle of InFamous Second Son (2014) is based on real places is enough to encourage exploration. Yet tourism should not be limited to these urban adaptations. All kinds of fictional game worlds can also be toured. Nintendo's The Legend of Zelda: Breath of the Wild (2017) takes place in the ancient kingdom of Hyrule - a location that has been depicted over the last three decades in various forms across the many games in the series. In the game, players can unlock a camera item that their character Link can use to take photos throughout the land. Functionally, the purpose of the camera is to take photos of "memory" locations related to the story and objects that can be added to an in-game compendium. But though there is no direct way to export the photos outside of the videogame console's ecosystem, players can use the screenshot function of the Nintendo Wii U or Switch to duplicate images of the photographs in their in-game album and share them online. Of course, players could also just screenshot their game without the visual indicators that show while using camera item, but the rhetoric of the diegetic photo or selfie as a specific object associated with memory and spatial experience lends a personal weight to the game's unique vistas. Through possessive spectatorship, curious players document experiences beyond the normal play of the game. In these moments, the game world transcends its functionality, and the gamer-tourist transforms space into place. And, as evidenced by tourism-centred objectives in recent games, recording/sharing functionality, and media being made that captures these experiences, game worlds are increasingly being made with the knowledge that players take pleasure in touring their landscapes.

\section{Bibliography}

Bell, C. \& Lyall, J. (2005). 'I was here': Pixelated evidence. In: D. Crouch, R. Jackson \& F. Thompson (eds.), The media and the tourist imagination: Converging cultures. London: Routledge. 


\section{Bobby Schweizer}

Bogost, I. \& Klainbaum, D. (2006). Experiencing place in Los Santos and Vice City. In: N. Garrelts (ed.), The culture and meaning of Grand Theft Auto, pp. 162-176. Jefferson: McFarland Press.

Book, B. (2003, July 20). Traveling through cyberspace: Tourism and photography in virtual worlds. Presented at the Tourism \& Photography: Still Visions Changing Lives, Sheffield. Retrieved from https://papers.ssrn.com/abstract=538182.

Bridge, G. \& Watson, S. (2008). City imaginaries. In: G. Bridge \& S. Watson (eds.), A companion to the city, pp. 5-17. Malden: John Wiley \& Sons.

Brown, P. (2016, November 23). Watch Dogs 2 review. Retrieved from www.gamespot.com/reviews/watch-dogs-2-review/1900-6416578/

Dinhopl, A. \& Gretzel, U. (2016). Selfie-taking as touristic looking. Annals of Tourism Research 57: 126-139.

Donald, J. (1999). Imagining the modern city. Minneapolis: University of Minnesota Press.

Dow, D.N. (2013). Historical veneers: Anachronism, simulation and art history in Assassin's Creed II. In: M.W. Kapell \& A.B.R. Elliott (eds.), Playing with the past: Digital games and the simulation of history, pp. 215-232. London: Bloomsbury Publishing.

Gordon, E. (2010). The urban spectator: American concept cities from Kodak to Google. Hanover: Dartmouth College Press.

Grubb, J. (2013, September 20). Modder explains how he got $4 \mathrm{~K}$ Grand Theft Auto IV screens that put GTA V to shame. Retrieved from https://venturebeat. com/2013/09/20/these-photo-realistic-4k-gta-iv-screens-put-gta-v-to-shame-gallery/ (03-06-2018).

Hamza, K. (1991, February). The killing cloud. The One (29): 40-41.

Jaguaribe, B. (2007). Cities without maps. In: A. Cinar \& T. Bender (eds.), Urban imaginaries: Locating the modern city, pp. 100-120. Retrieved from http://site. ebrary.com/id/10212637.

Jarvis,J. \&Houghton,D.(2016). Mafia 3:New Bordeaux VSNew Orleans: The city that inspired the game. Retrieved from www.youtube.com/watch?v=8WKX5duy7X0.

Kollar, P. (2016, November 14). Watch Dogs 2 review. Retrieved from www.polygon. com/2016/11/14/13620870/watch-dogs-2-review-playstation-4-ps4-xbox-onepc-windows-ubisoft (05-06-2018).

Löfgren, O. (2002). On holiday: A history of vacationing. Berkeley: University of California Press.

MacCannell, D. (1999). The tourist: A new theory of the leisure class, 2nd ed. Berkeley: University of California Press.

Miller, K. (2008). The accidental carjack: Ethnography, gameworld tourism, and Grand Theft Auto. Game Studies 8(1). Retrieved from http://gamestudies. org/0801/articles/miller.

Pearce, A. \& Sliva, M. (2016). Touring the real San Francisco in Watch Dogs 2. Retrieved from www.ign.com/videos/2016/10/10/touring-the-real-san-franciscoin-watch-dogs-2.

Plunkett, L. (2012, August 29). The joys of using games for virtual tourism. Retrieved from http://kotaku.com/5939108/the-joys-of-using-games-for-virtualtourism (30-03-2014).

Poremba, C. (2007). Point and shoot remediating photography in gamespace. Games and Culture 2(1): 49-58. 
Salmond, M. (2016). The mediation and fetishisation of the travel experience. In: C. Scarles \& J.-A. Lester (eds.), Mediating the tourist experience: From brochures to virtual encounters. London: Routledge.

Salmond, M. \& Salmond, J. (2016). The gamer as tourist: The simulated environments and impossible geographies of videogames. In: P. Long \& N.D. Morpeth (eds.), Tourism and the creative industries: Theories, policies and practice. London: Routledge.

Schweizer, B. (2013, Fall). Moving through videogame cities. Mediascape. Retrieved from www.tft.ucla.edu/mediascape/Fall2013_MovingThroughCities.html.

Smith, R. (2013, February 28). GTA 4 in 4k. Retrieved from www.flickr.com/photos/ 15539352@N02/8517614178/(17-06-2019).

Stapleton, D. (2016, November 23). Watch Dogs 2 review. Retrieved from www.ign. com/articles/2016/11/23/watch-dogs-2-review.

Upchurch, D. (1991, May). The killing cloud. ACE: Advanced Computer Entertainment (44): 60-62.

Urry, J. \& Larsen, J. (2011). The tourist gaze 3.0. London: Sage.

VortexStory. (2017). Driver VS Driv3r VS Real Life: Miami Map Comparison. Retrieved from www.youtube.com/watch?v=Gq4kTvaY3L4.

Westwood, S. \& Williams, J. (1997). Imagining cities: Scripts, signs, memory. London: Routledge.

Whalen, Z. (2006). Cruising in San Andreas: Ludic space and urban aesthetics in Grand Theft Auto. In: N. Garrelts (ed.), The meaning and culture of Grand Theft Auto, pp. 143-161. Jefferson: McFarland. 